\title{
Reduced early and late phase insulin response to glucose in isolated spiny mouse (Acomys cahirinus) islets: a defective link between glycolysis and adenylate cyclase
}

\author{
R. Nesher, E.Abramovitch and E. Cerasi \\ Department of Endocrinology and Metabolism, Hebrew University Hadassah Medical Center, Jerusalem, Israel
}

\begin{abstract}
Summary. The spiny mouse (Acomys cahirinus) exhibits low insulin responsiveness to glucose with a nearly absent early phase release. The alternative fuel-secretagogue glyceraldehyde $(10 \mathrm{mmol} / \mathrm{l})$ produced a maximal early insulin response in rat islets but failed to affect early response in Acomys; however, it potentiated the late insulin response in both species alike. Glucagon $(1.5 \mu \mathrm{mol} / 1)$ potentiated the early insulin response to intermediate $(8.3 \mathrm{mmol} / \mathrm{l})$ glucose in rat and Acomys islets by two- and four-fold, respectively. Glucose doubled cyclic AMP levels in rat islets but no significant response was noted in Acomys islets. Isobutylmethylxanthine $(0.1 \mathrm{mmol} / \mathrm{l})$ and forskolin $(25 \mu \mathrm{mol} / 1)$ caused a significant rise in islet cyclic AMP levels in both types of islets; however, neither agent restored the glucose stimulation of cyclic AMP in spiny mouse islets. Forskolin and isobutylmethylxanthine potentiated early
\end{abstract}

and late phase insulin release in both species; however, neither augmented the early response in the Acomys to the degree observed in rat islets. Thus: (1) A deficient link exists in Acomys between glycolysis and subsequent signals. (2) These islets contain a glucose-insensitive adenylate cyclase. (3) The early insulin response may be potentiated by direct activation of adenylate cyclase. (4) The glucose effects on early and late phase insulin release are probably mediated by distinct pathways. (5) In the spiny mouse the signals mediating the early response are deranged to a greater extent than those activating the late phase insulin release.

Key words: Biphasic insulin release, spiny mouse, acomys cahirinus, cyclic AMP, glucagon, glyceraldehyde.
The exocytotic event that results in insulin release from pancreatic $B$ cells is under the control of complex metabolic signals [1]. Upon stimulation with glucose, normal islets exhibit biphasic dynamics of insulin release, representing the net expression of the interaction between several regulatory events, including time-dependent inhibitory and potentiating signals [1-10]. Limited information exists regarding the nature of these regulatory signals.

The early stages of glucose intolerance in man are characterized by severe reduction in early phase insulin response to glucose, and a delayed and often reduced late phase response. The nature of the metabolic defect(s) responsible for the poor responsiveness of the B cell is unknown. The spiny mouse, Acomys cahirinus, exhibits such diabetic-like kinetics of insulin response to glucose in vivo and in vitro [11-15], and often develops glucose intolerance when raised in captivity. The spiny mouse is, therefore, a convenient animal model for mild Type 2 (non-insulin-dependent) diabetes. Using islets from this animal, it could thus be shown that the early phase of insulin release is more reduced than the late response $[12,14,15]$, and that a first phase insulin response can be partially restored by priming the islets with glucose for $20-60 \mathrm{~min}$, a finding that is pertinent also for glucose intolerant man $[16,17]$.

Cumulative evidence suggests that a normal first phase insulin response necessitates activation of $\mathrm{B}$ cell adenylate cyclase by glucose stimulation, resulting in a normal cyclic AMP response $[1,4,18,19]$. The cyclic AMP response of Acomys islets to glucose was found deficient [20]. In the present study we examined further the responsiveness of Acomys islets to a variety of secretagogues in an attempt to define the nature of the deficient signal that causes a low insulin response to glucose, with emphasis on agents that elevate the islet cyclic AMP concentration. The spiny mouse belongs to rodent species unrelated to any common laboratory animal. In previous studies we examined the overall rates of insulin response as well as its dynamics in this species and compared it to those seen in the rat and the mouse $[11-15,17]$. In the present study emphasis is given to the kinetics of insulin release rather than to its absolute magnitude when comparing results obtained in Acomys and in the control rat islets. 
Early Response

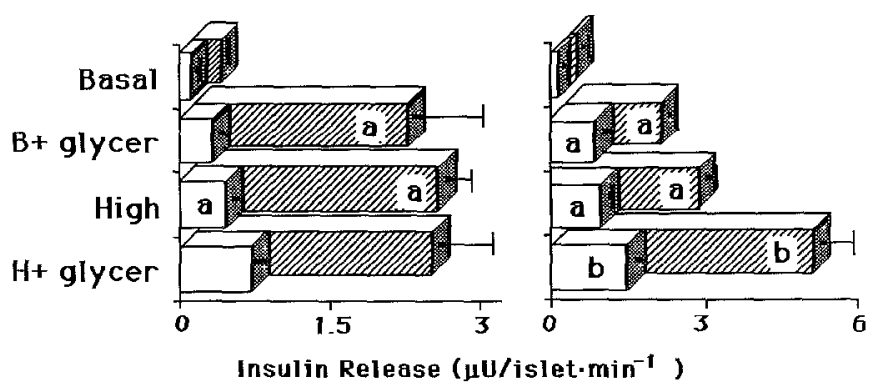

Fig.1. Effect of glyceraldehyde (glycer) on early (initial $10 \mathrm{~min}$ ) and late (subsequent $50 \mathrm{~min}$ ) insulin responses in rat (hatched bars) and Acomys (open bars) islets. Each bar represents mean ( \pm SEM) of $6-124$ observations of single islets incubated at basal $(\mathrm{B}, 3.3 \mathrm{mmol} / \mathrm{l})$ glucose: high $(\mathrm{H}, 16.7 \mathrm{mmol} / \mathrm{l})$ glucose, or where indicated, $10 \mathrm{mmol} / 1$ glyceraldehyde was added. Statistical significance is denoted by: $(a)$ designates $p<0.01$ compared to basal, and $(b)$ is $p<0.01$ compared to high glucose stimulus

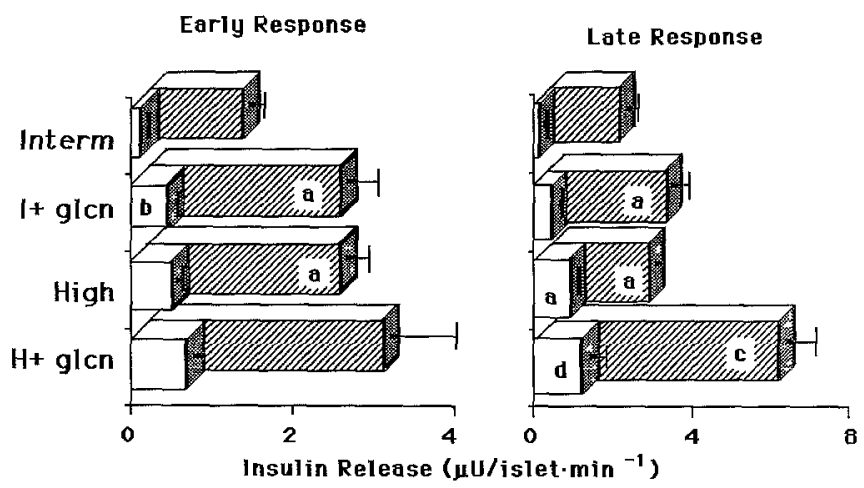

Fig. 2. Effect of glucagon (glcn) on early (initial $10 \mathrm{~min}$ ) and late (subsequent $50 \mathrm{~min}$ ) insulin response in rat (hatched bars) and Acomys (open bars) islets. Each bar represents mean ( \pm SEM) of 11-124 observations of single islets incubated at intermediate (I, $8.3 \mathrm{mmol} / \mathrm{l}$ ) glucose, high $(\mathrm{H}, 16.7 \mathrm{mmol} / \mathrm{l})$ glucose, or where indicated, together with $1.5 \mu \mathrm{mol} / 1$ glucagon. Statistical significance is denoted by: (a) designates $p<0.01$ compared to interm; $(b)$ is $p<0.05$ compared to interm; $(c)$ is $p<0.01$ compared to high; and $(d)$ is $p<0.05$ compared to high glucose stimulus

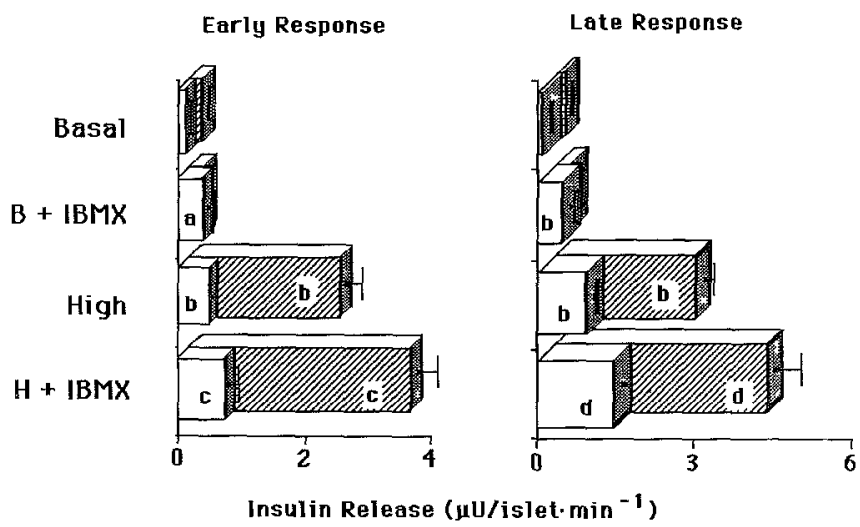

Fig.3. Effect of isobutylmethylxanthine (IBMX) on early (initial $10 \mathrm{~min}$ ) and late (subsequent $50 \mathrm{~min}$ ) insulin response in rat (hatched bars) and Acomys (open bars) islets. Each bar represents mean $( \pm$ SEM) of 11-124 observations of single islets incubated at basal ( $B$, $3.3 \mathrm{mmol} / \mathrm{l})$ glucose; high $(\mathrm{H}, 16.7 \mathrm{mmol} / \mathrm{l})$ or where indicated, together with $0.1 \mathrm{mmol} / 1$ isobutylmethylxanthine. Statistical significance is denoted by: (a) designates $p<0.05$; and $(b) p<0.01$ compared to basal; (c) $p<0.05$ compared to high; and (d) $p<0.01$ compared to high glucose stimulus

\section{Materials and methods}

Islets of Langerhans were obtained by collagenase digestion [21] from male Sabra rats weighing $150-250 \mathrm{~g}$ and from male or female Acomys cahirinus aged 8-15 months. The morning non-fasted plasma glucose levels in both rats and spiny mice ranged between $5.0-8.9 \mathrm{mmol} / \mathrm{l}$. All animals were bred and raised at the Hebrew University Animal Farm and maintained on free laboratory chow. The isolated islets were washed at $4^{\circ} \mathrm{C}$ in Hank's buffer saturated with $\mathrm{O}_{2} / \mathrm{CO}_{2}(95 \%: 5 \%)$, preincubated for $40 \mathrm{~min}$ at $37^{\circ} \mathrm{C}$ in Krebs Ringer bicarbonate buffer (KRB) containing $0.5 \%$ bovine serum albumin (BSA, fraction V, Sigma Chemicals Co., St. Louis, Mo, USA), and $3.3 \mathrm{mmol} / 1$ glucose, after which single islets were transferred to tubes containing $1.0 \mathrm{ml}$ $\mathrm{KRB}$, and incubated for 10 or $60 \mathrm{~min}$ in the presence of low $(3.3 \mathrm{mmol} / 1)$, intermediate $(8.3 \mathrm{mmol} / \mathrm{l})$, or high $(16.7 \mathrm{mmol} / \mathrm{l}) \mathrm{con}$ centration of glucose, with or without addition of the indicated agents. The incubation was terminated by reducing the temperature to $4^{\circ} \mathrm{C}$, the tubes were then centrifuged at $500 \mathrm{~g}$ for $2 \mathrm{~min}$, and the supernatant taken into tubes containing EDTA (final concentration $10 \mathrm{mmol} / \mathrm{l}$ ). The samples were stored at $-20^{\circ} \mathrm{C}$ until assayed.

Islet cyclic AMP levels were determined in parallel experiments, in which 10-20 islets were incubated under similar conditions for $5 \mathrm{~min}$. The buffer was then removed, $0.3 \mathrm{ml}$ of $50 \mathrm{mmol} / 1$ sodium acetate buffer ( $\mathrm{pH}$ 5.8) added and cyclic AMP extracted by boiling the islets for 2 min. A commercial cyclic AMP radioimmunoassay kit (Amersham International, Amersham, Buckinghamshire, U.K.), modified by acetylation to increase sensitivity, was used. The routinely obtained minimal detectable level ranged between 0.7 and $1.0 \mathrm{femtomol} / \mathrm{tube}$.

Insulin was determixled by standard radioimmunoassay using goat anti-guinea pig serum to separate bound and free insulin. Human insulin was used as standard in the Acomys assay, and rat insulin in the rat assay (both from Novo Research Laboratories, Bagsvaerd, Denmark) $[11-15,17]$. The minimal detectable dose for both assays ranged between $0.7-3 \mu \mathrm{U} / \mathrm{ml}$.

Insulin and cyclic AMP radioimmunoassays were processed using a four parameter sigmoid curve fitting programme. Late phase insulin response was expressed as values obtained over $60 \mathrm{~min}$ minus the amount released during the initial $10 \mathrm{~min}$ of incubation.

\section{Statistical analysis}

Statistical analysis was performed using one-way ANOVA followed by Dunnett's comparison at $95 \%$ or $99 \%$ confidence level.

\section{Results}

The decreased responsiveness of Acomys islets to glucose $(16.7 \mathrm{mmol} / \mathrm{l})$ is illustrated in Figure 1: first phase response was $19 \%$, second phase release $37 \%$ that of rat islets (both $p<0.01$ ). The early insulin response in the spiny mouse islets was usually 10 times the release rate observed at basal glucose, while rat islets normally responded to high glucose by a 30 -fold rise. Glyceraldehyde $(10 \mathrm{mmol} / \mathrm{l})$ in combination with $3.3 \mathrm{mmol} / 1 \mathrm{glu}$ cose produced maximal early insulin response in rat islets. In contrast, in the spiny mouse islets the triose failed to significantly augment the early insulin response, and no significant amplification of the stimulatory effect of $16.7 \mathrm{mmol} / \mathrm{l}$ glucose could be demonstrated (Fig. 1).

A different picture emerged during late phase insulin secretion: glyceraldehyde induced significant insulin release in the presence of basal glucose concentra- 
tion, and amplified the late insulin response to $16.7 \mathrm{mmol} / 1$ glucose both in the rat and the spiny mouse islets (Fig. 1); however, in absolute terms the response of Acomys islets to the combined glucose-glyceraldehyde stimulus was still only $30 \%$ that of rat islets $(p<0.01)$.

Several non-metabolizable secretagogues exert synergistic effects with glucose on insulin secretion, which is particularly marked during first phase response [1-3, 10]. Thus, arginine $(5 \mathrm{mmol} / \mathrm{l})$ increased the early insulin response of rat islets to $8.3 \mathrm{mmol} / 1$ glucose by $30 \%$ and to $16.7 \mathrm{mmol} / 1$ by $60 \%$; the amino acid was ineffective, however, in augmenting the early or late insulin response in Acomys islets at either glucose concentration (data not shown). Results were different when glucagon $(1.5 \mu \mathrm{mol} / 1)$ was used to stimulate the islets (Fig.2). Glucagon amplified the early insulin response to $8.3 \mathrm{mmol} / 1$ glucose in rat and spiny mouse islets by 2 and 4-fold respectively ( $p<0.01$ for rat and $p<0.05$ for Acomys islets). At $16.7 \mathrm{mmol} / 1$ glucose, the effect of glucagon was modest and statistically not significant ( $20 \%$ increase in rat and $40 \%$ increase in Acomys islets). Glucagon also exerted a potentiating effect on glucoseinduced late insulin response in both species; however, while rat islets responded to a glucagon stimulus with 1.6-fold potentiation of late insulin response to $8.3 \mathrm{mmol} / 1$ glucose and 2.3 -fold augmentation to $16.7 \mathrm{mmol} / 1$ glucose ( $p<0.01$ in both cases), Acomys islets failed to respond to glucagon when added to intermediate $(8.3 \mathrm{mmol} / 1)$ glucose and demonstrated only $40 \%$ potentiation of the insulin response to high $(16.7 \mathrm{mmol} / \mathrm{l})$ glucose $(p<0.05)$ (Fig. 2).

Glucagon is believed to induce insulin release primarily by raising the B cell cyclic AMP level. Therefore, the ability of cyclic AMP to augment glucose-mediated insulin release in Acomys islets was further examined. Table 1 shows that rat islets responded to a glucose stimulus by doubling their cyclic AMP content $(p<0.01)$; no significant response to glucose could be

Table 1. Cyclic AMP levels in isolated rat and Acomys islets stimulated with glucose, isobutylmethylxanthine (IBMX) and forskolin

\begin{tabular}{|c|c|c|c|}
\hline & \multicolumn{2}{|c|}{ Ambient glucose } & \multirow{2}{*}{$\begin{array}{l}\text { Significance of } \\
\text { glucose effect }\end{array}$} \\
\hline & $\begin{array}{l}3.3 \mathrm{mmol} / \mathrm{l} \\
\text { (femtomol/i }\end{array}$ & $\begin{array}{l}16.7 \mathrm{mmol} / 1 \\
\left.\mathrm{~min}^{-1}\right)\end{array}$ & \\
\hline \multicolumn{4}{|l|}{ Rat } \\
\hline Control & $2.9 \pm 0.3^{\mathrm{a}}$ & $5.3 \pm 0.9$ & $p<0.01$ \\
\hline IBMX & $6.9 \pm 0.6$ & $9.2 \pm 0.8$ & $p<0.05$ \\
\hline Forskolin & $79.2 \pm 28.0$ & $81.3 \pm 22.1$ & NS \\
\hline \multicolumn{4}{|l|}{ Acomys } \\
\hline Control & $2.6 \pm 0.2$ & $2.9 \pm 0.7$ & NS \\
\hline IBMX & $13.9 \pm 2.1$ & $16.4 \pm 3.0$ & NS \\
\hline Forskolin & $68.1 \pm 13.3$ & $62.3 \pm 4.2$ & NS \\
\hline
\end{tabular}

(a) Values are mean ( \pm SEM) of $6-12$ observations in which $10-20$ islets were incubated for $5 \mathrm{~min}$ with or without IBMX $(0.1 \mathrm{mmol} / \mathrm{l})$ or forskolin $(25 \mu \mathrm{mol} / 1)$ in low or high glucose. Significance was tested for glucose effect (shown) and for the IBMX and forskolin effect vs untreated control islets, which was significant in all experiments $(p<0.05$ or less)

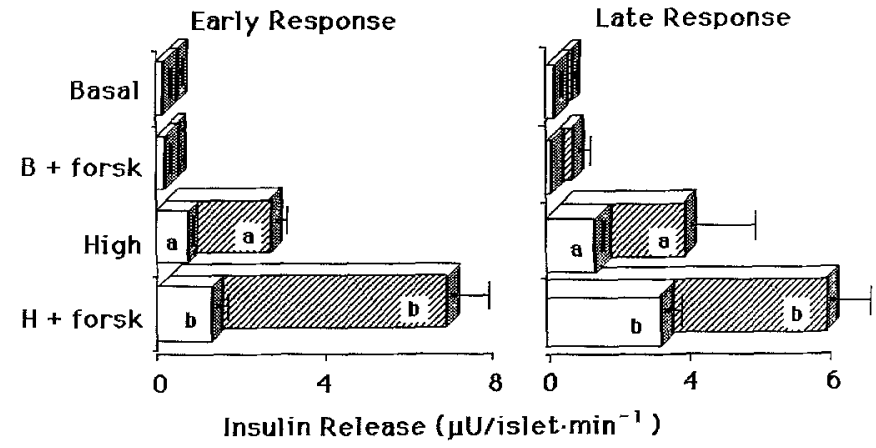

Fig.4. Effect of forskolin (forsk) on early (initial $10 \mathrm{~min}$ ) and late (subsequent $50 \mathrm{~min}$ ) insulin response in rat (hatched bars) and $\mathrm{Aco}-$ mys (open bars) islets. Each bar represents mean ( \pm SEM) of 13-124 observations of single islets incubated at basal $(B, 3.3 \mathrm{mmol} / \mathrm{l})$ glucose; high $(H, 16.7 \mathrm{mmol} / \mathrm{l})$ or where indicated, together with $25 \mu \mathrm{mol} / 1$ forskolin. Statistical significance is denoted by: (a) designates $p<0.01$ compared to basal; $(b) p<0.01$ compared to high glucose stimulus

demonstrated in Acomys islets. Glucagon together with intermediate $(8.3 \mathrm{mmol} / \mathrm{l})$ glucose induced only small and statistically insignificant increase in cyclic AMP levels compared to the effect of glucose alone $(7.47 \pm 0.79$ vs $5.53 \pm 0.54 \mathrm{femtomol} /$ islet $\cdot 5 \mathrm{~min}^{-1}$ in rat islets and $3.48 \pm 0.17$ vs $2.96 \pm 0.37 \mathrm{femtomol} /$ islet $\cdot 5 \mathrm{~min}^{-1}$ in Acomys islets). The phosphodiesterase inhibitor isobutyl methylxanthine (IBMX) increased the cyclic AMP content at basal glucose in both types of islets (Table 1); however, it failed to affect the Acomys islet cyclic AMP response to glucose. IBMX also significantly stimulated both early and late insulin response to glucose $(16.7 \mathrm{mmol} / \mathrm{l})$ in rat as well as Acomys islets, the amplification being of similar magnitude in both cases $(50 \%$, $p<0.05$ or less) (Fig.3). Finally, maximal stimulation of the adenylate cyclase system by forskolin $(25 \mu \mathrm{mol} / \mathrm{l})$ resulted in an approximately 25 -fold increase in basal cyclic AMP levels in rat and Acomys islets (Table 1). As shown in Figure 4, this was accompanied by significant potentiation of the early (2-fold) and late (2.3-fold) insulin responses to $16.7 \mathrm{mmol} / 1$ glucose in Acomys islets ( $p<0.01$ in both cases). Despite this, the absolute early insulin secretion rates in the spiny mouse islets were still significantly less than those obtained in rat islets with glucose alone. Late insulin response to the combined glucose-forskolin stimulus reached levels observed in rat islets stimulated by glucose alone, while remaining at $40 \%$ of the response to combined glucose-forskolin stimulus.

\section{Discussion}

The spiny mouse (Acomys cahirinus) has attracted considerable interest as an animal model for Type 2 diabetes, since this rodent tends to develop obesity and glucose intolerance in captivity, some animals presenting with non-ketotic moderate hyperglycaemia $[11-15,17]$. An interesting feature of these animals, and in this respect they differ markedly from other 
obese rodents, is the low insulin response to glucose observed both in vivo [13-15] and in vitro $[14,15,17]$. The pancreatic islets of Acomys contain normal or supranormal amounts of insulin $[14,15]$, yet, the rate of hormone release is reduced compared to rat and mouse islets [11-17]. More important, the dynamics of insulin release are strikingly reminiscent of those seen in glucose intolerant man $[15,17,20]$, in that first phase response to glucose is grossly reduced, while second phase response is less impaired [17]. We have previously shown that if Acomys islets are primed with glucose to generate time-dependent potentiation, the kinetics of the insulin response to a subsequent glucose stimulus are markedly improved, a near-normal first phase release being elicited [17]. It seems, therefore, that the deficient first phase release of the $\mathrm{AcO}-$ mys B cell is the reflection of a deficiency in the glucose stimulus-secretion coupling which is amenable to correction under certain conditions.

It is generally accepted that the stimulation of insulin release by glucose is mediated by factors linked to the metabolism of the hexose in the B cell [1]. The lack of stimulation of first phase release in Acomys islets by glyceraldehyde, shown here, indicates that the defective coupling in these islets is not at the level of hexose transport or phosphorylation but beyond the triose step. As would be expected from previous observations that second phase response to glucose was less deranged [17], late insulin release is markedly stimulated during prolonged exposure $(60 \mathrm{~min}$ ) of Acomys islets to glyceraldehyde. Such findings as well as other observations from our group $[2,5,7]$ and others $[3,4,8,9]$ suggest that the mechanisms that control first and second phase insulin release are distinct and dissociable.

It is presently believed that cyclic AMP plays a key role as gain modulator of metabolic sequences leading to insulin release, possibly by sensitizing them to small changes in cytosolic $\mathrm{Ca}^{2+}$ levels $[3,4,19]$. Work from this laboratory [23] and elsewhere [4, 24-26] presented evidence to suggest that the stimulation of B cell cyclic AMP levels by glucose is particularly important for the expression of normal first phase insulin release. By the present direct measurements of islet cyclic AMP we were able to confirm earlier observations using prelabelling of islets with ${ }^{3} \mathrm{H}$-adenine [20], that the adenylate cyclase system of the spiny mouse is essentially glucoseinsensitive, in keeping with the blunted first phase insulin response to the sugar. Although cyclic AMP levels could be raised by the phosphodiesterase inhibitor IBMX and the adenylate cyclase stimulator forskolin in Acomys islets to the same extent as in rat islets, complete insensitivity of the enzyme to glucose was retained in either case.

Failure of glucose to elevate the islet cyclic AMP content is obviously not the sole reason for the glucose insensitivity of the insulin release, since in the presence of IBMX Acomys islets contained as much cyclic AMP as glucose-stimulated rat islets without, however, eliciting a corresponding first phase insulin response. When extreme elevation of islet cyclic AMP was induced by forskolin or by dibutyryl cyclic AMP (data not shown), first phase release could, however, be elicited. Thus, the secretory mechanisms in these islets are capable of responding to the amplifying effect of cyclic AMP. This may reflect the fact that the glucose signal for first phase release is extremely weak in Acomys B cells, and therefore only supraphysiologic cyclic AMP levels may amplify it sufficiently to reach the threshold for secretion. Another possibility is that the sensitivity of the secretory mechanisms to cyclic AMP is reduced in these B cells. In preliminary experiments, we have tested this possibility by overnight exposure of spiny mouse islets to dibutyryl cyclic AMP + IBMX, then subjecting them to a glucose stimulus; no improvement in insulin response could be demonstrated (unpublished observations).

Glucagon is also believed to stimulate insulin release by the activation of B cell adenylate cyclase [22]. In our hands, glucagon augmented the islet cyclic AMP level by only $20-30 \%$. Despite this insignificant stimulation, and in contrast with the results of incubations in the presence of IBMX where a major elevation of islet cyclic AMP was obtained, glucagon amplified markedly the first phase insulin response in Acomys islets. We have no explanation for this discrepancy, other than that glucagon may have non-cyclic AMP mediated effects such as the activation of membrane phosphoinositide hydrolysis and generation of inositol 1, 4, 5 triphesphate $[1,3,4]$, or alternatively that a small, for insulin release critically specific, cyclic AMP pool is stimulated by the hormone.

It is evident from the above discussion that the exact nature of the deficient coupling of glucose metabolism to first phase insulin release in Acomys B cells is still unciear. Data presented in this paper identifies at least one site of derangement in signal transmission, namely the link between glycolysis and adenylate cyclase. The adequate cyclic AMP response to IBMX and to forskolin indicates that sufficient amounts of the enzyme are present. Although other metabolic aberrations in distal stages of the stimulus secretion coupling cannot be ruled out, it is possible that a single, common aberrant post-glycolytic signal is responsible for the deficient activation of $B$ cell adenylate cyclase as well as of a parallel sequence leading to insulin release, cyclic AMP amplifying the "read-out" of this signal [3, 4]. One such common defect may be the inability of glucose to raise the $\mathrm{B}$ cell cytosolic $\mathrm{Ca}^{2+}$ level. Indeed, both glucose-induced insulin release and cyclic AMP stimulation depend on $\mathrm{Ca}^{2+}[1,2,4,18,19]$. Furthermore, high cyclic AMP levels (induced by e.g. forskolin) may facilitate the effect of glucose on cytosol $\mathrm{Ca}^{2+}[1,2,4,18$, 19] hence the potentiation of first phase release observed in our experiments. Obviously, direct measurements of $\mathrm{B}$ cell cytosolic $\mathrm{Ca}^{2+}$ levels are needed to validate such a hypothesis.

Acomys islets demonstrate a reasonable rate of late insulin response to glucose as well as to most other secretagogues. Although the late insulin response critically 
depends on ambient glucose levels, and is similarly sensitive to cyclic AMP [27] it is clearly activated by a different mechanism than the early insulin response [1-5, $8,24-26,28$ ], and in the present study, no attempt was made to relate it to cyclic AMP levels. We have recently proposed that the late response is the expression of the effect of a time-dependent regulatory loop on insulin release [2] and have demonstrated that this loop is functionally intact in islets from the spiny mouse [17], as it seems to be in glucose intolerant people [16]. The activation of protein kinase $\mathrm{C}$ by diacylglycerol has been proposed to be important for late phase insulin release and time-dependent potentiation $[3,4,29]$. In the case of Acomys islets, the previous activation of diacylglyceroldependent protein kinase $\mathrm{C}$ by glucose priming could, therefore, be the factor that improves the insulin response, bypassing the defective signal for first phase release. Studies have been initiated to test this hypothesis.

Acknowledgements. The authors wish to acknowledge Mrs. Esther Greenberg for her meticulous work in the cyclic AMP assay. This work was supported in part by grants from the Hadassah Hospital Hebrew University Joint Fund; the Israel Ministry of Health - Chief Scientist's Office; the Wolfson Family Charitable Trust; and the George Grandis Fund for Medical Research.

\section{References}

1. Prentki M, Matschinsky FM (1987) $\mathrm{Ca}^{2+}$, cAMP and phospholipid - derived messengers in coupling mechanisms of insulin secretion. Physiol Rev 67: 1185-1248

2. Nesher R, Cerasi E (1987) Biphasic insulin release as the expression of combined inhibitory and potentiating effects of glucose. Endocrinology 121: 1017-1027

3. Rasmussen H (1986) The calcium messenger system. New Engl J Med 314: 1164-1169

4. Rasmussen $\mathrm{H}$, Isales $\mathrm{K}$, Takuwa $\mathrm{Y}$, Takuwa N, Barrett $\mathrm{P}$, Zawalich W (1988) The cellular basis for short term memory in endocrine systems. In: Woody CD, Alkon DL, McGaugh JL (eds) Cellular mechanisms of conditioning and behavioral plasticity. Plenum Press, New York, pp 3-9

5. Cerasi E, Fick G, Rudemo M (1974) A mathematical model for the glucose induced insulin release in man. Europ $J$ Clin Invest 4: 267-278

6. Efendic S, Lins PE, Cerasi E (1979) Potentiation and inhibition of insulin release in man following priming with glucose and with arginine - effect of somatostatin. Acta Endocrinol (Copenh) 90: 259-271

7. Grill V, Adamson U, Cerasi E (1978) Immediate and time dependent effects of glucose on insulin release from rat pancreatic tissue. Evidence for different mechanisms of action. J Clin Invest 61: 1034-1043

8. O'Connor MDL, Landahl H, Grodsky GM (1980) Comparison of storage - and signal-limited models of pancreatic insulin secretion. Am J Physiol 238: R378-R398

9. Ashby JP, Shirling D (1980) Evidence for priming and inhibitory effects of glucose on insulin secretion from isolated islets of Langerhans. Diabetologia 18: 417-421

10. Nesher R, Waldman L, Cerasi E (1984) Time-dependent inhibition of insulin release: glucose-arginine interaction in perfused rat pancreas. Diabetologia 26: 146-149

11. Cameron DP, Stauffacher W, Orci L, Amherdt M, Renold AE (1972) Defective immunoreactive insulin secretion in Acomys cahirinus. Diabetes 21: 1060-1071
12. Gutzeit A, Rabinovitch A, Karakash C, Staufacher W, Renold AE, Cerasi E (1974) Evidence for decreased sensitivity to glucose of isolated islets from spiny mice (Acomys cahirinus). Diabetologia 10: 661-665

13. Gutzeit A, Rabinovitch A, Studer PP, Trueheart PA, Cerasi E (1974) Decreased intravenous glucose tolerance and low plasma insulin response in spiny mice (Acomys cahirinus). Diabetologia 10: $667-670$

14. Rabinovitch A, Gutzeit A, Grill V, Kikuchi M, Renold AE, Cerasi $\mathrm{E}$ (1975) Defective insulin secretion in the spiny mouse (Acomys cahirinus). Possible value in the study of the pathophysiology of diabetes. Isr J Med Sci 11: 730-737

15. Rabinovitch A, Gutzeit A, Renold AE, Cerasi E (1975) Insulin secretion in the spiny mouse (Acomys cahirinus). Dose and time kinetic studies with glucose in vivo and in vitro. Diabetes 24 : 1094-1100

16. Cerasi E (1975) Potentiation of insulin release by glucose in man. III. Normal recognition of glucose as potentiator in subjects with low insulin response and mild diabetes. Acta Endocrinol (Copenh) 79:511-534

17. Nesher R, Abramovitch E, Cerasi E (1985) Correction of diabetic pattern of insulin release from islets of spiny mouse (Acomys cahirinus) by glucose priming in vitro. Diabetologia 288: 233-236

18. Wollheim CD, Sharp GWG (1981) Regulation of insulin release by calcium. Physiol Rev 61: 914-973

19. Henquin JC (1985) The interplay between cyclic AMP and ions in the stimulus-secretion coupling in pancreatic B-cells. Arch Int Physiol Biochem 93: 37-488

20. Grill V, Cerasi E (1979) The metabolism of cyclic AMP and glucose in isolated islets of Acomys cahirinus. Diabetologia 16: 47-50

21. Lacy PE, Kostianovsky M (1967) Method for the isolation of intact islets of Langerhans from rat pancreas. Diabetes 16: 35-39

22. Van Schravendijk CFH, Foriiers A, Hooghe-Peters EL, Rogiers V, De Meyts P, Sodoyez JC, Pipeleers DG (1985) Pancreatic hormone receptors on islet cells. Endocrinology 117: 841-844

23. Krausz Y, Eylon L, Cerasi E (1987) Calcium-binding proteins and insulin release. Differential effects of phenothiazines on first - and second-phase secretion and on islet cAMP response to glucose. Acta Endocrinol (Copenh) 116: 241-246

24. Zawalich W, Zawalich K, Rasmussen H (1984) Insulin secretion: combined tolbutamide, forskolin and TPA mimic action of glucose. Cell Calcium 5: 551-558

25. Zawalich W, Cote SB, Diaz VA (1986) Influence of cholecystokinin on insulin output from isolated perifused pancreatic islets. Endocrinology 119: 616-621

26. Zawalich W, Takua N, Takua Y, Diaz VA, Rasmussen H (1987) Interactions of cholecystokinin and glucose in rat pancreatic islets. Diabetes $36: 426-433$

27. Cerasi E (1981) Differential actions of glucose on insulin release: reevaluation of a mathematical model. In: Cobelli $\mathrm{C}$, Bergman RN (eds) Carbohydrate Metabolism. John Wiley, New York, p 3

28. Zawalich W, Brown C, Rasmussen H (1983) Insulin secretion: combined effects of phorbol ester and A23187. Biochem Biophys Res Commun 117: 448-455

29. Zawalich WS (1988) Time-dependent potentiation of insulin release induced by alpha-ketoisocaproate and leucine in rats: possible involvement of phosphoinositide hydrolysis. Diabetologia 31: 435-442

Received: 4 January 1989

and in revised form: 18 May 1989

Dr. R. Nesher

Department of Endocrinology and Metabolism

Hadassah University Hospital

P.O.Box 12000

91120 Jerusalem

Israel 